\title{
Direct nephrotoxic effects produced by venoms of Sri Lankan cobra, Russell's viper and hump nosed viper Mangala Gunatilake', R L Jayakody ${ }^{2}$, P Angunawela ${ }^{3}$, A de Tissera ${ }^{4}$ \\ 'The Ceylon Journal of Medical Science 2003; 46: 61-66
}

\begin{abstract}
Nephrotoxicity is the principal cause of death following Russell's viper envenomation. Envenomation following the bite of several other snakes is also known to cause nephrotoxicity. The nephrotoxicity can be due to direct effects of venom or secondary to circulatory disturbances (eg. ischaemia), which these patients often manifest. As separating out the contributions of direct toxic effects and ischaemic effects are difficult in the in vivo situation, experiments were carried out using the kidney slice model to study and compare the direct toxic effects of venom of cobra, Russell's viper and hump nosed viper.
\end{abstract}

The effect of cobra venom (CV) on rat kidney slices and the effects of Russell's viper venom (RVV) and hump nosed viper venom (HNVV) on rabbit kidney slices were examined. Healthy male animals were anaesthetized and kidneys were harvested. Kidneys were decapsulated, bisected and sliced. Rat kidney slices were incubated with $\mathrm{CV}$ and rabbit kidney slices were incubated with RVV and HNVV for different time periods. Rat and rabbit kidney slices were incubated with $0.9 \%$ sodium chloride as the control. At the end of each observation period kidney slices were preserved for light and electron microscopy (LM and EM).

When CV was used, complete necrosis was seen in proximal and distal convoluted tubular cells (PCT and DCT). When rabbit kidney slices were incubated with RVV for 4 hours there was complete necrosis of glomeruli and PCT with the preservation of the basement membrane. LM and EM changes were mostly confined to PCT when HNVV was used.
The results of this experiment provide evidence that the venoms studied produce direct damage on renal tissue. Different areas of the nephron are differentially susceptible to the effects of the three venoms.

Key words : direct nephrotoxicity, Russell's viper venom, cobra venom, hump nosed viper venom, kidney slice model

\section{Introduction}

The death rate due to snake bite envenomation in Sri Lanka is one of the highest in the world (1). These fatalities are often caused by cobra, Russell's viper and the common krait. Though cobra and krait venom are more potent than Russell's viper venom, Russell's viper is the most dreaded snake in the island (2) and it is responsible for $40 \%$ of deaths due to envenomation (1).

Although death following Russell's viper envenomation could be due to different reasons (shock, haemorrhage, disseminated intravascular coagulation, neurotoxicity, respiratory failure or acute renal failure), nephrotoxicity leading to acute renal failure has been identified as the principal cause (1). In one study it was found that envenomation by Russell's viper contributes for $49 \%$ of cases of acute renal failure reported at the National Hospital of Sri Lanka (3). Envenomation following the bite of several other snakes (e.g. cobra, pit vipers and sea snake) is also known to cause nephrotoxicity $(4,5)$.

The development of rephrotoxicity in envenomation can be due to direct effects of venom or secondary to circulatory disturbances (ischaemia), which these patients often show. Separating out the contribution of direct

\footnotetext{
'Departments of Physiology, 2Pharmacology, 3Pathology, Faculty of Medicine, University of Colombo, Sri Lanka. 'Formerly of Dept. of Pathology, Medical Research Institute, Colombo 8. Sri Lanka.
} 
nephrotoxicity and ischaemic effects towards the development of acute renal failure is difficult in the in vivo situation. Hence, experiments were carried out using the kidney slice model in order to study the direct nephrotoxic effects of venom of Russell's viper (RVV), hump nosed viper (HNVV) and cobra (CV). This in vitro model had been used by other workers to demonstrate direct nephrotoxic effect of Vipera russelli russelli (6).

\section{Material and Methods}

\section{Animals}

The protocol reported here is part of a detailed investigation on effects of venom on renal structure and function $(7,8,9)$. In this protocol studying the direct toxic effects of venom, CV was tested in rats and RVV and HNVV were tested in rabbits.

For the experiments using rats, healthy SpragueDawley male animals (approximately 8 months of age) weighing 200-300 g were obtained from an inbred colony maintained at the animal house of the Faculty of Medicine, Colombo. These rats were housed under tropical laboratory conditions and given a pelleted diet with sweet potato.

For the experiments using rabbits, local crossbred white male animals (approximately 9 months of age), weighing 1 to $2 \mathrm{~kg}$ were used. Rabbits were kept in the animal house for 2 weeks prior to the experiments. They were given a diet of carrot and green leaves. Ethical clearance for the experiments was obtained from the institutional review body.

\section{Source of venom}

CV, RVV and HNVV were obtained from the reptilium of the National Zoological Garden, Dehiwela, Sri Lanka. The snakes were identified by the curator and the venom was milked by him. Venom was milked into pre-weighed, sterilized, universal bottles and care was taken to prevent the venom mixing with saliva. The venom containing universal bottles were kept in ice and brought to the laboratory. In the laboratory the venom was weighed and divided into 2 or 3 aliquots and stored at $-70^{\circ} \mathrm{C}$.

\section{Anaesthesia of animals and harvesting of kidneys}

Rats were anaesthtized by ether inhalation for harvesting of kidneys. Kidneys were harvested through a mid ventral laparotomy. During the dissection anaesthesia was maintained by injecting diazepam intramuscularly at a dose of $0.3 \mathrm{mg} / \mathrm{kg}$. After harvesting the kidneys animals were killed by a cardiac puncture.

Rabbits were anaethetized using intravenous thiopentone sodium ( $20 \mathrm{mg} / \mathrm{kg}$ body weight). During dissection anasthesia was maintained by ether inhalation using a mask. Once the animal was anaesthetized the kidneys were harvested through a mid ventral laparotomy and subsequently the animals were killed by a cardiac puncture.

The kidneys were decapsulated and bisected using sterile instruments while keeping in $0.9 \%$ sodium chloride. Uniform slices of $0.3 \mathrm{~mm}$ thickness were obtained from the bisected kidneys using a tissue slicer. Rat kidney slices were incubated with $10 \mathrm{mg} / \mathrm{ml}$ of CV and rabbit kidney slices were incubated with $10 \mathrm{mg} / \mathrm{ml}$ of RVV and HNVV separately for 1, 2,3 or 4 hours in a water bath at $37^{\circ} \mathrm{C}(\mathrm{n}=5$ for each stage). This dose of venom $(10 \mathrm{mg} / \mathrm{ml})$ was decided based on the experiments by Soe-Soe et al., (6). In their experiments varying doses of RVV (Vipera russelli russelli) were used (300 $\mathrm{ng} / \mathrm{ml}, 2.5 \mathrm{mg} / \mathrm{ml}$, $5 \mathrm{mg} / \mathrm{ml}$ and $10 \mathrm{mg} / \mathrm{ml}$ ). They found effects only at doses of $5 \mathrm{mg} / \mathrm{ml}$ and $10 \mathrm{mg} / \mathrm{ml}$. Hence, for our experiments only the $10 \mathrm{mg} / \mathrm{ml}$ dose was used. Kidney slices incubated with $0.9 \%$ sodium chloride were used as controls. After incubating for different time periods ( 1 hour, 2 hours, 3 hours or 4 hours), kidney slices were fixed in modified Boins solution or with $2 \%$ gluteraldehyde for light microscopy (LM) or electron microscopy (EM) respectively. Pathological changes in kidney slices were expressed as percentages. The percentage of change (degeneration or necrosis) were categorized as described below after examining ten fields under low and high dry power $(10 \times 20$, $10 \times 40$ ) in two slides. 
changes in $5-10 \%$ of structures - very mild changes in $11-33 \%$ of structures - mild changes in $34-66 \%$ of structures - moderate changes in $67-85 \%$ of structures - marked changes in $86-100 \%$ of structures - severe

\section{Results}

\section{Effects of CV}

In the rat kidney slices incubated with $\mathrm{CV}$ the glomeruli were histologically normal in appearance. The proximal convoluted tubular cells (PCT) showed complete necrosis 2, 3 and 4 hours after incubation. The nuclei of the distal convoluted tubular cells (DCT) were pyknotic at 4 hours after incubation. Marked degeneration was there in the medulla at 3 and 4 hours after incubation. At electron microscopy both normal and collapsed capillary loops in the glomerular tufts were seen. The ultrastructure of the PCT cells was completely destroyed. However, the basement membrane was preserved (Figure 1). Changes were more marked with the increase in incubation time.

\section{Effects of RVV}

In the rabbit kidney slices incubated with RVV, glomerular tuft of the surface glomeruli showed necrosis and rest of the glomeruli had pyknotic nuclei at 3 and 4 hours after incubation. Histologically, the PCT showed complete necrosis at 2, 3 and 4 hours after incubation. All the cortical structures (PCT, DCT and glomeruli) showed complete necrosis at 4 hours after incubation. The renal medulla in the specimens was histologically normal in appearance. Electron microscopy showed complete destruction of glomerular tufts and the cells of the PCT (Figures 2 and 3 ). However, the basement membrane of the cells was preserved.

\section{Effects of HNVV}

In the rabbit kidney slices incubated with HNVV, the glomeruli showed occasional pyknotic nuclei at 3 and 4 hours after incubation. There was severe necrosis of the PCT epithelium with occasional viable cells at 3 and 4 hours after incubation. Appearance of small endocytic vacuoles was visible in the cytoplasm of the podocyte and endothelial cells of the glomeruli in some areas when kidney slices were incubated with HNVV for 4 hours. Most of the mitochondria and their membranes of the PCT cells were completely destroyed. Appearance of vacuoles and myeloid bodies in the PCT cell cytoplasm was also observed (Figure 4).

\section{Appearance of control specimens}

Glomeruli in the control specimens were normal in appearance. Necrotic changes were not observed in the PCT or DCT cells. Electron microscopically swollen mitochondria and disappearance of cristae were noticed in a few PCT cells.

\section{Discussion}

These experiments confirm production of direct damage on the kidney tissue by the venoms of cobra, Russell's viper and hump nosed viper found in Sri Lanka. The damage was most severe with RVV and least with HNVV. Similar findings using venom of Vipera russelli siamensis on rat kidney slices have been reported by Tin-Nu-Swe et al.,(10). They describe extensive renal damage including damage to the glomeruli when rat kidney slices were incubated with $5 \mathrm{mg} / \mathrm{ml}$ of Russell's viper venom. Soe-Soe et al., (1990) also have observed necrosis of PCT when rabbit kidney slices were incubated with 5 and $10 \mathrm{mg} / \mathrm{ml}$ of Russell's viper venom. However, they describe only about damage to the PCT cells (6). Our findings contrast with those of Ratcliffe et al., who did not dernonstrate any renal damage with venom of Thai cobra (Naja kauothio) on isolated perfused rat kidney model (11). The direct toxic effect of HNVV has not been subjected to experiments earlier. However, the observation is that venom of hump nosed viper is less nephrotoxic than the venoms of Russell's viper and the cobra.

The variation in the direct nephrotoxic effects of venoms may be due to the different amounts of phospholipase $A_{2}$ present in them or due to differences in their iso-enzymes (12).

\section{Acknowledgements}

We would like to thank National Science Foundation and Kidney Research Fund of the 
University of Colombo for financing this project. We also thank Dr D S Kodikara, Veterinary Surgeon and $\mathrm{Mr} \mathrm{H}$ Molligoda, former curator of the reptilium of National Zoological Gardens for helping us to obtain venom.

\section{References}

I. De Silva A. (1990). Venomous snakes, their bites and treatment in Sri Lanka In:. Snakes of Medical Importance. Gopalakrishnakone P., Chou L. M. eds. Venom and toxin research group, National University of Singapore. 1990; 479-550.

2. Phillips R. E., Theakston R. D. G., Warrell D.A., Galigedara Y., Abesekera D. T. D. J., Dissanayake P., Hutton R. A., Aloysius D. J. Paralysis, rhabdomyolysis and haemolysis caused by bites of Russell's viper (Vipera russelli pulchella) in Sri Lanka: Failure of Indian (Haffkine) antivenom. Quarterly Journal of Medicine. 1988;257:691-716.

3. Ariaratnam C. A., Meyer W. P., Perera G., Eddleston M., Kularatne S. A. M., Atapattu W., Sheriff R., Richards R. M., Theakston R D J., Warrell D. A. A new monospecipic ovine Fab fragment antivenom for treatment of envenoming by the Sri Lankan Russell's viper (Daboia russelli russelli): A preliminary dose-finding and pharmacokinetic study. American Journal of Tropical Medicine and Hygiene. 1999; 61: 259-265.

4. Sheriff M. H, R. (1983). Renal disease due to snake-bite and its management. Ceylon Medical Journal. 1983; 28: 190-198.

5. De Silva A., Wijekoon A. S. B., Jayasena L., Abesekera C K., Cheng-Xin Bao, Hutton R. A., Warrell D. A. Haemostatic dysfunction and acute renal failure following envenoming by Merrem's hump-nosed viper (Hypnale hypnale) in Sri Lanka: first authenticated case. Transactions of the Royal Society of Tropical Medicine and Hygiene. 1994; 88: 209-212.

6. Soe-Soe, Than-Than, Khin-Ei-Han. The nephrotoxic action of Russell's viper (Vipera russelli) venom. Toxicon. 1990; 28: 461-467.
7. Mangala Gunatilake. Testing renal function in rats and rabbits after injecting venom of Russell's viper (Vipera russelli pulchella), cobra (Najanaja) and hump nosed viper (Hypnale hypnale). PhD Thesis, University of Colombo, 2000.

8. Gunatilake M., De Mel T., Fernando C., Angunawela P., Tissera De A., Welihinda J. Time of onset and mechanism of nephrotoxicity after envenoming rats with Russell's viper venom and cobra venom. Journal of the Ceylon College of Physicians. 1996; 29: 29-35.

9. Gunatilake M., Jayakody R. L., Angunawela P., Tissera De A. Direct nephrotoxic effect of Sri Lankan Russell's viper venom - an experimental study using in vitro models. Ceylon Journal of Medical Science. 2002; 45(2): 59-70.

10. Tin-Nu-Swe, Khin-Myint-Myint-Kyaw, Htein Win, Khine-Win, Than-Than-Htwe. Russell's viper venom fractions and nephrotoxicity. South east Asian Journal of Tropical Medicine and Public Health. 1997; 28: 657-663.

11. Ratcliffe P. J., Pukrittayakamee S., Ledingham J. G. G., Warrell D. A. Direct nephrotoxicity of Russell's viper venom demonstrated in the isolated perfused rat kidney. American Journal of Tropical Medicine and Hygiene. 1989; 40: 312319.

12. Warrell D. A. Snake venoms in science and clinical medicine: 1. Russell's viper: biology, venom and treatment of bites. Transactions of the Royal Society of Tropical Medicine and Hygiene. 1989; 83: 732-740. 


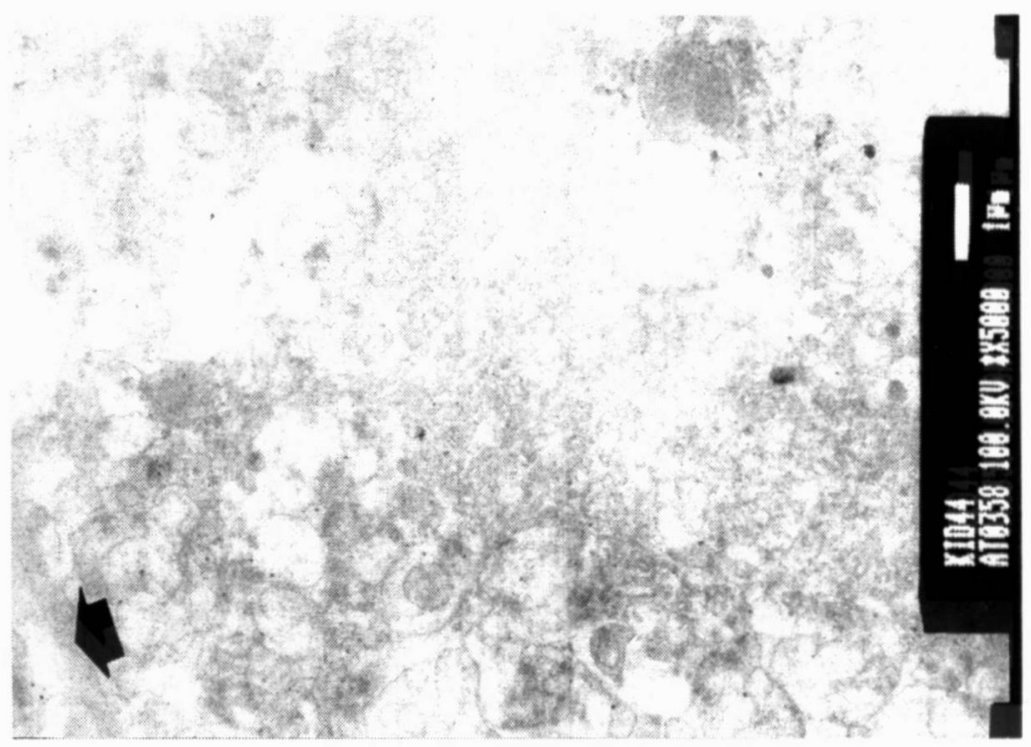

Figure 1. Electron micrograph appearance of rat kidney slices when incubated with cobra venom for 4 hours. Complete destruction of the ultrastructure of the PCT cells with the preservation of the basement membrane is seen (arrowhead).

Magnification X 10000, bar $=1 \mathrm{~mm}$.

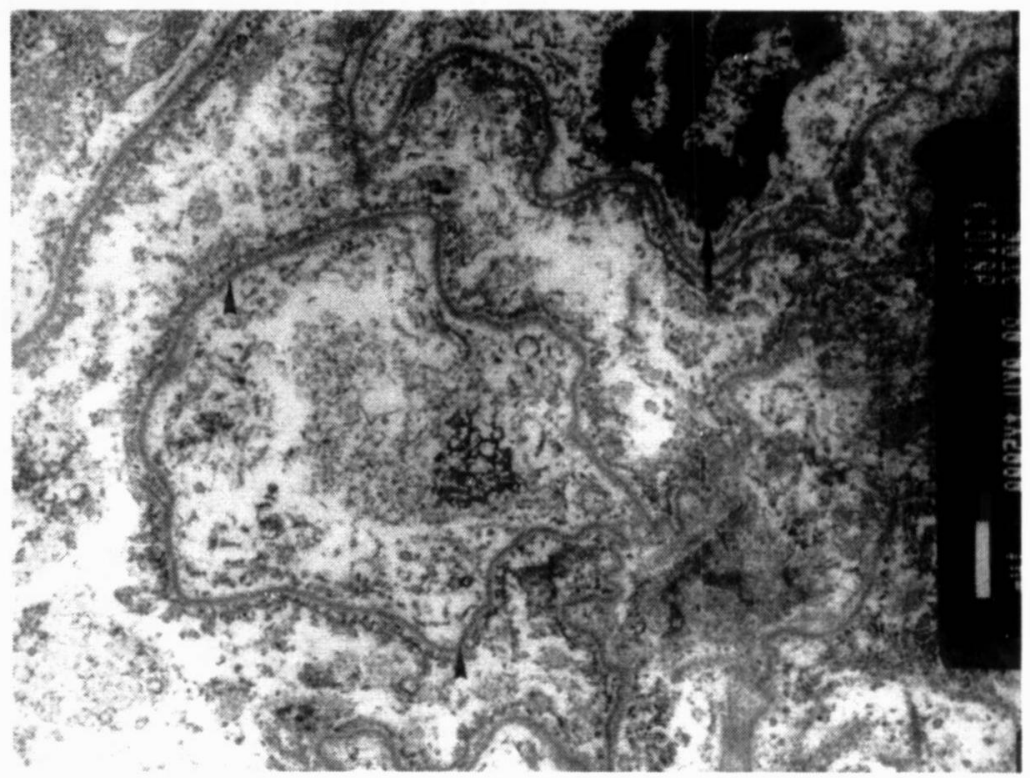

Figure 2. Electron micrograph appearance of the completely destroyed ultrastructure of a glomerulus of a rabbit kidney slice incubated with Russell's viper venom for 4 hours. Basement membrane is preserved (arrowhead). Clumping of chromatin in the nucleus of a white blood cell is seen (arrow). Magnification X10000, bar $=1 \mathrm{~mm}$. 


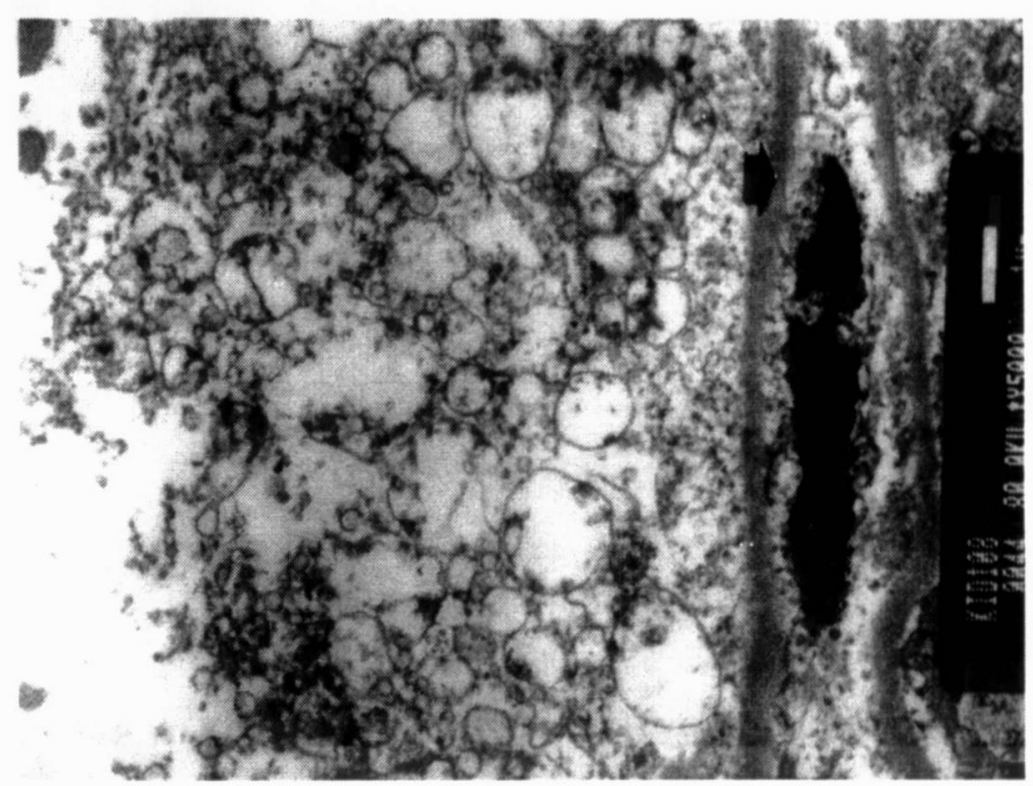

Figure 3. Electron micrograph of the completely destroyed ultrastructure of a PCT cell when rabbit kidney slices were incubated with Russell's viper venom for 4 hours. Basement membrane of the cell is preserved (arrowhead).

Magnification $X 10000$, bar $=1 \mathrm{~mm}$.

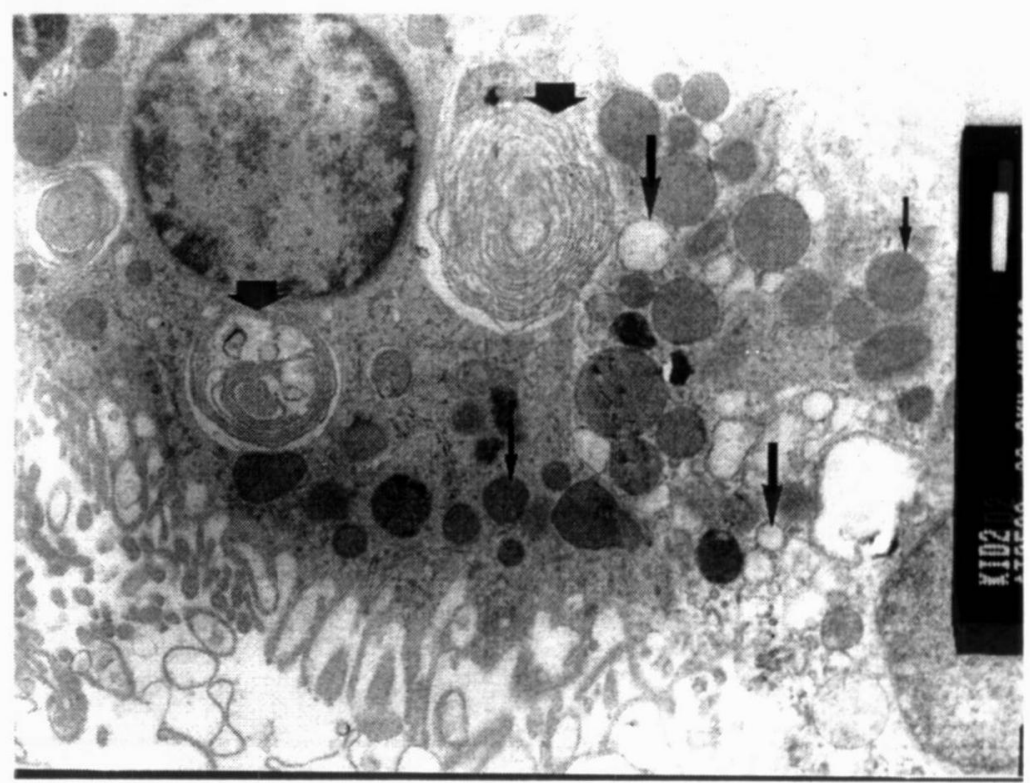

Figure 4. Electron micrograph appearance of a PCT cell of a rabbit kidney slice when incubated with hump nosed viper venom for 4 hours. Appearance of myelin bodies; concentrically laminated electron-dense bodies which represents altered lysosomes (arrow heads), dense bodies (small arrows) and vacuoles (large arrows) are seen.

Magnification X 10000, bar $=1 \mathrm{~mm}$. 